\title{
Evolução da escolaridade esperada no Brasil ao longo do século XX
}

\author{
Otaviano Helene
}

Universidade de São Paulo

\section{Resumo}

Este trabalho apresenta dois procedimentos para calcular o número de anos de escolaridade fornecidos pelo sistema educacional brasileiro. Um dos procedimentos é baseado nas taxas de conclusão dos ensinos fundamental, médio e superior. Tal procedimento, que depende do conhecimento da população nas várias faixas etárias e do número de concluintes de cada um dos níveis educacionais, foi utilizado para as estimativas no período posterior a 1962.0 outro procedimento é baseado no número de anos de estudo declarado pela população adulta, tal como divulgado pelo Instituto Brasileiro de Geografia e Estatística (IBGE), e foi utilizado para estimar o número de anos fornecidos pelo sistema educacional em períodos mais remotos. 0 bom acordo entre os resultados obtidos com os dois métodos no período entre 1962 e 1999 demonstra que eles são consistentes. A combinação dos dois procedimentos fornece resultados para um período de cerca de 90 anos, iniciando-se em meados da década de 1920. As incertezas dos resultados, estimadas a partir tanto das flutuações dos dados utilizados, quanto das aproximações numéricas que foram feitas, são da ordem de 3\%. Alguns detalhes dos cálculos são apresentados ao final, nos apêndices. As variações no número de anos de escolaridade, quando maiores do que as incertezas estimadas, estão associadas a eventos políticos, sociais ou educacionais que marcaram o período analisado.

\section{Palavras-chave}

Educação média - Escolaridade esperada - Anos completos de estudo.

\footnotetext{
Correspondência:

Otaviano Helene

Universidade de São Paulo

Instituto de Física -

Departamento de Física Experimental

Caixa postal 66318

05314-970 - São Paulo/SP

otaviano@if.usp.br
} 


\title{
The evolution of expected schooling in Brazil in the 20th century
}

Otaviano Helene

University of São Paulo

\begin{abstract}
This work presents two procedures to calculate the number of years of schooling afforded by the Brazilian education system. One of the procedures is based on the rates of completion at fundamental, secondary and higher education. This procedure, which relies on knowledge of the population distribution across several age groups and on the number of graduates at each education level, was used in the estimates related to the period before 1962. The other procedure is based on the number of years of schooling declared by the adult population, made available by the Brazilian Institute of Geography and Statistics (IBGE), and was employed to estimate the number of years of schooling achieved by the education system in earlier periods. The good agreement between the results obtained with the two methods for the period between 1962 and 1999 demonstrates that they are consistent. The combination of the two procedures can give the results for a period of around 90 years, starting in the mid-1920s. The uncertainties of the results estimated both from fluctuations in the data used and from the numerical approximations made, are around 3\%. Some of the details of the calculations are presented at the end of the work, in appendixes. The variations in the number of years of schooling, when larger than the uncertainties estimated, are associated to political, social or educational events that characterize the historical period analyzed.
\end{abstract}

\section{Keywords}

Secondary education - Expected schooling - Years of completed schooling.

Contact:

Otaviano Helene

Universidade de São Paulo

Instituto de Física

Departamento de Física Experimental

05314-970 - São Paulo/SP

otaviano@if.usp.br 
A média do número de anos de estudo fornecidos pelo sistema educacional é um indicador bastante importante da escolarização futura da população adulta, bem como do funcionamento do sistema educacional em determinado momento.

Há alguns procedimentos para estimar a escolaridade esperada de uma população com base nas características presentes no sistema escolar. 0 procedimento adotado pela UNESCO (2009) tem sido bastante utilizado, principalmente em estudos que comparam características de diferentes países (cf. RAM, 1999, e referências lá citadas). Ele é baseado nas taxas de matrícula das diferentes coortes etárias de determinado ano, informação nem sempre disponível para longos períodos de tempo. Além disso, tal procedimento estima o número de anos de permanência na escola, mesmo que essa permanência corresponda à repetição de uma mesma série e não ao número de séries completadas. Procedimentos baseados em modelos de fluxo (KLEIN, 2003), bastante adotados no Brasil, dependem de muitas informações de difícil acesso, em especial para períodos mais remotos.

Com o objetivo de superar a dificuldade para encontrar dados detalhados sobre 0 sistema escolar, sobretudo em períodos remotos, podemos fazer estimativas suficientemente precisas para embasar conclusões qualitativas utilizando dados sistematizados e divulgados por diversas instituições.

Este trabalho apresenta duas metodologias para o cálculo da escolaridade média esperada fornecida pelo sistema educacional, desde o início do ensino fundamental até o final dos cursos de graduação, bem como os resultados obtidos. A escolaridade média esperada deve ser entendida como o número de anos de estudo que o sistema escolar forneceria para a população se mantido inalterado.

Em uma das metodologias adotadas, foram utilizados os números de concluintes de cada ciclo escolar e informações relativas à população nas diferentes faixas etárias. Nesse caso, conseguimos estimativas da escolaridade média fornecida pelo sistema escolar a partir de 1962. Para estimativas de anos anteriores, foram utilizadas as informações referentes ao número de anos de estudo da população obtidas e divulgadas pelo Instituto Brasileiro de Geografia e Estatística (IBGE) em diversos levantamentos. Combinando o número de anos de estudo informado e a idade do respondente, podemos estimar como era o sistema escolar em anos bem anteriores. Como os dois procedimentos fornecem resultados para um longo período em comum (entre 1962 e 1999), foi possível verificar a consistência dos dois métodos.

Assim, obteve-se a escolaridade média fornecida pelo sistema educacional brasileiro desde meados da década de 1920 até 2007. As várias irregularidades encontradas na evolução da escolaridade média esperada nesse período, tais como momentos de estagnação, retrocesso ou crescimento mais intenso, coincidem com fatos que marcaram significativamente a história do país.

Os dados referentes ao número de concluintes em cada nível escolar foram obtidos em diversos Anuários Estatísticos do IBGE, nas Sinopses Estatísticas da Educação Básica e no sítio Edudatabrasil, do Instituto Nacional de Estudos e Pesquisas Educacionais Anísio Teixeira (Inep). Dados populacionais, inclusive os referentes ao número declarado de anos de estudo da população, têm como origem censos, estimativas da população e pesquisas nacionais por amostra de domicílios (PNADs) divulgadas pelo IBGE. Quando um mesmo dado apresentou discrepância entre as fontes consultadas, utilizou-se a média simples entre os diferentes valores. Nos casos de ausência de dados para alguns anos ou faixas etárias, foram utilizadas médias aritméticas dos mesmos dados correspondentes a períodos ou faixas etárias próximas. Incertezas provenientes dos procedimentos adotados e dos dados utilizados foram estimadas e os resultados constam nos Apêndices. Todos os 
sítios eletrônicos foram consultados entre março e julho de 2010.

Os procedimentos adotados neste trabalho não são significativamente diferentes, em termos de precisão dos resultados obtidos, daqueles adotados ou recomendados pela UNESCO (2009) ou por outros pesquisadores (BEHRMAN, 1987; RAM, 1999). Entretanto, devemos observar que, em alguns casos (cf. BEHRMAN, 1987), não se considera a possibilidade de evasão escolar ao longo de um ciclo, o que pode criar alguma tendenciosidade nas estimativas feitas.

Tem-se, aqui, um duplo objetivo: apresentar os dois métodos complementares para avaliar o número médio de anos de escolarização fornecidos pelo sistema escolar e analisar sua evolução ao longo de um período de cerca de 90 anos.

\section{Estimativa das taxas de conclusão de cursos}

Esta seção apresenta o método adotado para calcular as taxas de conclusão de determinado nível educacional utilizado na seção seguinte para calcular a escolarização média esperada fornecida pelo sistema educacional.

A taxa de conclusão de um nível educacional $(P)$ pode ser estimada pela razão entre o número de concluintes, independentemente da idade, e a população na faixa etária correspondente à idade típica das pessoas ao completarem aquele nível:

$$
P \approx \frac{1}{N_{\langle i\rangle}} \sum_{i \geq i_{0}} n_{i}=\frac{n_{n}}{c_{n}}
$$

onde $n_{i}$ é o número de pessoas que completam determinado nível educacional com idade $i, i_{0}$ é a idade mínima que uma pessoa deve ter para completar aquele nível de ensino e $N_{\langle i\rangle}$ é a população com idade $<i>$, onde $<i>$ é a idade média daqueles que completam o nível educacional em questão. Nessa equação, tanto $n_{i}$ como $N_{\langle i\rangle}$ correspondem aos dados de um m e s m o ${ }^{\prime}$ ano. (A dedução dessa expressão e as estimativas das incertezas provenientes do procedimento constam no Apêndice A). 0 termo $\sum_{i \geq i_{0}} n_{i}$ é o número total de concluintes do nível escolar em questão em determinado ano, identificado por $n_{n}$, e $c_{n}$ é a população em um ano de coorte etária correspondente àquele mesmo nível. Assim, a taxa de conclusão pode ser estimada pela razão entre o número de concluintes e a população na faixa etária correspondente. Devemos observar que $P$ é também a probabilidade de que uma pessoa conclua o nível educacional em questão se forem mantidas inalteradas as características do sistema educacional. Assim, $P$ representa uma medida do desempenho quantitativo do sistema educacional no ano em que foi calculado, incluídas nesse desempenho as taxas de engajamento dos estudantes, a evasão escolar e as taxas de reprovação.

Os números de concluintes dos ensinos fundamental (ou do ginásio, antes de sua fusão com o ensino primário), médio e superior entre 1962 e 2007 aparecem na Tabela 1, com eventuais interpolações ou médias de dados de diferentes fontes, quando necessárias. A população em diferentes faixas etárias para alguns anos do período estudado aparece na Tabela 2, cuja fonte são os dados divulgados pelo IBGE. As idades apresentadas na Tabela 2 correspondem à idade média de um grupo etário. Por exemplo, 16,5 anos é a idade média daqueles que têm 16 anos completos. As estimativas das incertezas dos dados das tabelas 1 e 2, tal como apresentado no Apêndice B, são suficientemente pequenas (da ordem de 1\%) para não comprometerem qualitativamente as conclusões ou os resultados obtidos.

As estimativas das taxas de conclusão dos três níveis de ensino considerados neste trabalho no período entre 1962 e 2007, calculadas pela Equação (1), aparecem na Figura 1. Entretanto, 
como as mudanças em um sistema educacional não têm reflexos imediatos, diluindo-se ao longo de alguns anos, com a finalidade de reduzir as irregularidades dos dados apresentados e impedir que um comportamento atípico possa dificultar o entendimento do todo, utilizou-se, na construção da Figura 1, a média móvel de três valores sucessivos dessas taxas de conclusão.

Entre os objetivos deste trabalho está o acompanhamento da evolução do sistema educacional brasileiro em um período de cerca de 90 anos. Assim, para saber se uma variação do indicador adotado é significativa ou se tem origem em variações espúrias dos dados ou erros provocados pelos métodos, foram estimadas as incertezas dos resultados. Como apresentado no Apêndice A, as incertezas provenientes da metodologia e das aproximações adotadas, inferiores a 1\%, são bem menores do que as incertezas cujas origens são os próprios dados, da ordem de 3\%, estimadas no Apêndice B. Assim, variações da escolaridade esperada maiores do que aquela incerteza podem ser consideradas significativas; variações inferiores a 3\% do valor podem ter como origem flutuações provocadas pelos dados utilizados.

\section{Estimativa da escolaridade média fornecida pelo sistema educacional com base no número de concluintes}

Para estimar o número médio esperado de anos de escolaridade fornecidos pelo sistema educacional, foi calculado o seguinte fator:

$$
\mathrm{E}=15 \frac{n_{s}}{c_{s}}+12 \frac{n_{m}-n_{s}}{c_{m}}+9 \frac{n_{f}-n_{m}}{c_{f}}+4 \frac{c_{i}-n_{f}}{c_{j}}
$$

onde $n_{f}, n_{m}$ e $n_{s}$ são os números de concluintes dos níveis fundamental, médio e superior, respectivamente, e $c_{i}, c_{j}, c_{f}, c_{m}$ e $c_{s}$, as populações nas idades correspondentes ao início do ensino fundamental, à média no ensino fundamental e ao final dos ensinos fundamental, médio e superior, respectivamente. Todos esses valores devem corresponder a um mesmo ano do calendário. (Antes da fusão dos antigos primário e ginásio, utilizou-se o número de conclusões deste último nível de ensino.)

Como se pode observar, o fator $E$ é uma combinação linear das taxas de conclusão dos diferentes níveis escolares, cujos pesos são próximos ao número de anos de permanência no sistema até a conclusão daquele nível. Por exemplo, o primeiro termo do lado direito da Equação (2) corresponde à contribuição para a média de anos de estudo da população daqueles que concluíram o ensino superior $\left(n_{s}\right)$, sendo que o fator 15 corresponde ao número total de anos de estudo estimado dessas pessoas a partir do início do ensino fundamental. Os demais pesos não são exatamente iguais à duração total da escolaridade até a conclusão do nível em questão, pois, como é típico no Brasil, há evasão escolar significativa ao longo de todo o percurso escolar e não apenas ao final de cada ciclo. Por exemplo, o termo $12 \frac{n_{m}-n_{s}}{c_{m}}$ corresponde à contribuição para a escolaridade esperada da população por aquele contingente que concluiu o ensino médio, mas não o ensino superior, dado por $n_{m}-n_{s}$. 0 fator numérico 12 corresponde aos 11 anos de escolaridade aumentados empiricamente de uma unidade, para dar conta daqueles que iniciam e não concluem o ensino superior. 0 termo seguinte corresponde ao ensino fundamental, com a adição de um ano para dar conta daqueles que iniciam o ensino médio, mas não o concluem. 0 último termo da Equação (2) corresponde à hipótese de que aqueles que iniciam o ensino fundamental, mas não o completam, permanecem, em média, 4 anos na escola. Devemos notar que essas correções, embora inexatas, fornecem excelentes estimativas, como demonstra a comparação entre os resultados obtidos por esse procedimento e os resultados obtidos pelo procedimento descrito na seção seguinte. 
0 fator $E$ é bastante próximo da escolaridade média esperada da população fornecida pelo sistema escolar. Apesar da arbitrariedade da ponderação dos vários termos da Equação (2), ela corresponde muito aproximadamente à escolaridade declarada da população que frequentou o sistema escolar no período considerado, como veremos mais adiante. Além disso, ainda que possa haver vieses estatísticos, o fator $E$ permite acompanhar a evolução do sistema educacional, desde que aqueles possíveis vieses não se alterem significativamente ao longo dos anos.

0 fator $E$, entretanto, não reflete exatamente o sistema escolar de determinado ano, pois pessoas com níveis diferentes de escolaridade que deixam o sistema escolar em dado ano do calendário refletem o sistema educacional em períodos diferentes. Por exemplo, uma pessoa que conclui o ensino fundamental em 2000 reflete como era o sistema entre 1993 e 2000, período em que essa pessoa o frequentou (supondo não haver defasagem entre idade e série), enquanto alguém que concluiu o ensino superior no mesmo ano reflete o sistema educacional entre 1986 e 2000. Assim, para evitar que esse fato leve-nos a atribuir alguma causa a uma variação intensa da escolaridade esperada em um curto período de tempo, cada valor de $E$ foi substituído pela média móvel de um conjunto de 5 anos adjacentes, identificada por $<E>$. Uma possibilidade mais rigorosa seria considerar o período de permanência na escola dos concluintes dos diferentes níveis educacionais. Entretanto, considerando-se as incertezas estimadas, da ordem de 3\%, utilizar ou não esse procedimento não altera os resultados de forma significativa. Assim, optou-se pelo procedimento mais simples da média móvel.

É importante observar que não foram consideradas, nas estimativas da escolarização média da população, a educação infantil, a educação de adultos e jovens fora da idade apropriada para a frequência do ensino regular e a pós-graduação.
0 resultado obtido está apresentado na Figura 2 e é, portanto, uma aproximação da escolaridade média esperada da população que frequentou o sistema escolar em um período em torno do ano indicado na abscissa daquela figura. As barras em torno de cada ponto correspondem à estimativa das incertezas.

Podemos observar, na Figura 2, quatro períodos bem marcantes: um crescimento da escolaridade média fornecida pelo sistema educacional até 1975 , seguido de um período de estagnação e redução; um novo período de crescimento, seguido, novamente, de um novo período de estagnação e redução. Essas e outras variações do sistema educacional serão analisadas na seção intitulada Discussão.

\section{Estimativas da escolarização com base no número declarado de anos de estudo}

Um dos dados levantados e divulgados pelo IBGE é a escolaridade declarada das pessoas em diferentes faixas etárias. A partir desse tipo de informação, podemos investigar como eram os sistemas educacionais em períodos mais antigos, além de confrontar, para períodos mais recentes, tal informação com os resultados obtidos a partir do procedimento descrito na seção anterior.

Consideremos uma coorte etária de idade média $I$ que, no ano $A$, tem escolaridade média $e$ ( $e$ é o número de séries concluídas). Supondo que a escolarização dessas pessoas tenha-se iniciado aos 7 anos, sua escolaridade média representa o desempenhodo sistema educacional por volta do ano

$$
A^{\prime} \approx A-I+e / 2+7+d
$$

onde $d$ é a defasagem entre idade e série. $\mathrm{Ou}$ seja, $e$ é a escolaridade média fornecida pelo sistema educacional brasileiro no ano $A$ '.

As fontes de informações sobre o sistema escolar em determinado ano são múltiplas. Por exemplo, pessoas com 4 anos de escolaridade e 
60 anos de idade em 1980 frequentaram a escola por volta de $1980-60+2+7+2=1931$ (supondo 2 anos de defasagem entre idade e série), isto é, refletem como era o sistema educacional em 1931. Igualmente, pessoas com 64 anos de idade em 1980 e 12 anos de escolaridade média forneceriam informação sobre o sistema educacional no mesmo ano de 1931.

A estimativa da Equação (3) é válida desde que a população considerada não venha a aumentar sua educação escolar posteriormente ao levantamento feito, ou seja, desde que a idade média da coorte etária considerada seja superior à idade média da população a partir da qual o aumento da escolaridade é não significativo. Para investigar essa idade, podemos examinar como varia o número médio de anos de estudo com a idade. Essa variação é mostrada na Figura 4, correspondente aos dados da PNAD de 2008. Entre os 10 e os 18 anos de idade, a escolaridade média da população aumenta cerca de 0,7 ano para cada ano adicional de idade, indicando que uma fração significativa da população naquela faixa etária permanece na escola. Entre os 18 e os 19 anos, esse aumento cai para cerca de 0,3 , e, entre os 19 e os 22 anos, para aproximadamente 0,1 , observação consistente com o fato de que a frequência à escola diminui com a idade. Depois dos 22 anos, a variação da escolaridade da população com a idade é decrescente. Podemos supor, portanto, que a contribuição para a escolaridade média da população por pessoas que continuam estudando após a idade de 22 anos é muito pequena, uma vez que tanto a porcentagem de pessoas como o número adicional de anos de estudo que elas venham a adquirir também são pequenos. Assim, a estimativa da escolaridade da população dada pela Equação (3) é aceitável desde que a idade $I$ da coorte examinada seja superior a 22 anos. Levando em conta essa limitação, a aplicação da Equação (3) foi restrita a pessoas com idade superior a essa faixa etária.

É interessante observar que o crescimento da escolaridade declarada da população até os 22 anos reflete a taxa de inclusão de jovens no sistema educacional e as taxas de aprovação; o decrescimento após os 22 anos ilustra o desenvolvimento do sistema educacional brasileiro no passado.

A Figura 5 mostra a escolaridade esperada $e$, considerando-se informações divulgadas pelo IBGE para pessoas em grupos etários com mais de 22 anos de idade. A abscissa corresponde ao valor de $A$ ' na Equação (3).

\section{Combinação dos resultados obtidos pelos dois métodos}

A escolaridade média da população apresentada na Figura 2 foi estimada a partir das taxas de conclusão. Os dados apresentados na Figura 5 foram estimados com base em declarações do número de anos de estudo de diferentes coortes etárias da população adulta. Há um período, entre o início da década de 1960 e final da década de 1990, para o qual há resultados obtidos pelos dois procedimentos. Como é possível observar comparando-se as Figuras 2 e 5, esses resultados comuns são consistentes quando consideramos as incertezas estimadas, da ordem de 3\%. Nos dois casos, a escolaridade média fornecida pelo sistema escolar no início da década de 1960 é de cerca de 5,5 anos. A partir daí, em ambos os casos, a escolaridade cresce até aproximadamente 7,0 a 7,5 anos em meados da década de 1970, quando inicia um período de estagnação. Tal período perdura até o início da década de 1990, quando, novamente, observa-se um período de crescimento da escolaridade esperada calculada pelos dois procedimentos. Esse período de crescimento perdura até o final da década de 1990, atingindo, em ambos os casos, um valor próximo a 9,5 anos de escolaridade.

As pequenas diferenças entre os resultados obtidos pelos dois métodos no período em que há dados em comum confirmam que a estimativa das incertezas, de 3\%, é realista e permite combinar os resultados dos dois métodos no período entre 1962 e 1999. Essa combinação é apresentada na Figura 6, sendo 
que, no período em comum, adotou-se a média dos resultados encontrados pelos dois métodos. As barras de incerteza foram mantidas em 3\%, mesmo para o período em que há resultados fornecidos pelos dois métodos.

\section{Discussão}

A Figura 6 mostra o número médio de anos de estudo fornecidos pelo sistema educacional brasileiro $(<E>)$ em um período de aproximadamente 90 anos. Embora haja uma incerteza, para mais ou para menos, da ordem de 3\% nos valores obtidos, é possível alguma análise qualitativa dos resultados, desde que ela respeite essa margem de incerteza.

Existem correlações entre variações da escolaridade média fornecida pelo sistema educacional brasileiro $(\langle E>)$ e outros fatos da realidade nacional. Identificar essas correlações, como é feito a seguir, não corresponde a um estudo histórico da educação ou do país. Além disso, a existência de uma correlação não implica, necessariamente, uma relação de causa e efeito. 0 que se pretende é fornecer subsídios para estudos que possam ajudar no entendimento dos efeitos que fatos importantes possam ter sobre a educação e identificar quais deles podem propiciar a evolução de nosso sistema escolar.

A primeira característica observável na Figura 6, em ordem cronológica, é um crescimento de $<E>$ até meados da década de 1930. Esse crescimento coincide com os movimentos educacionais ocorridos do início do século XX, marcados pelas atuações de Anísio Teixeira, Fernando de Azevedo e Lourenço Filho, entre outros. 0 comportamento observado de $\langle E>$ em meados da década de 1930 demonstra uma estagnação de nosso desenvolvimento educacional, coincidindo com a profunda crise econômica mundial e as crises políticas nacionais do mesmo período, aí incluído o golpe de 1937, o qual consolidou as forças que tomaram o poder em 1930 (FAUSTO, 1984).
Posteriormente, há uma retomada do crescimento que se inicia por volta de 1940 e perdura até meados de década de 1960. Durante esse período há, aparentemente, uma fase de crescimento menos intenso em meados da década de 1940, coincidindo com a 2a Guerra Mundial.

A retomada de um crescimento mais intenso ocorre no início da década de 1950 e dura até o início da década de 1960. No final desse período, há novamente uma estagnação ou mesmo redução da escolaridade média esperada fornecida pelo sistema educacional brasileiro, coincidente, nesse caso, com outro período de crise nacional, que se iniciou com a renúncia do então presidente em 1961 e culminou com o golpe militar de 1964.

0 crescimento da escolaridade esperada entre os inícios das décadas de 1940 e 1960 é o mais longo de todo o período analisado e, em sua segunda metade, coincide com o pragmatismo no pensamento educacional brasileiro (MENDONÇA et al., 2006).

0 crescimento é retomado ao final da década de 1960, momento bem marcado na política brasileira, inclusive na política educacional (ROTHEN, 2008). Entretanto, esse período de crescimento foi bastante curto, acabando no final da década de 1970 . Se, no início desse período, o crescimento coincide com a ideologia tecnocrática na ditadura militar (FERREIRA Jr.; BITTAR 2008), em meados dessa mesma década, o crescimento coincide com o fim do exame de admissão ao ginásio e a fusão deste com o ensino primário. Assim, estudantes represados passaram a fluir mais livremente pelo sistema escolar, dando origem a uma espécie de transbordamento e a um significativo crescimento do número de conclusões do ensino fundamental por volta de 1975, quatro anos após a criação do ensino fundamental.

Posteriormente, inicia-se um novo e longo período no qual a escolarização fornecida à população pelo sistema educacional estagnouse. Esse período coincide com o esgotamento dos modelos econômico e político do período 
ditatorial e estende-se por toda a década de 1980, período marcado também por longa crise econômica. Tal crise econômica é claramente ilustrada pela variação da renda per capita no período (veja Figura 3), acabando na mesma época em que se encerra o período mais longo de estagnação do sistema educacional.

0 período da ditadura militar apresentou três fases: um baixo crescimento de $<E>$ no seu início, um alto crescimento intermediário e um retrocesso nos seus anos finais. Combinando esses três períodos, o crescimento médio no período militar situa-se próximo ou mesmo ligeiramente abaixo do crescimento médio da escolarização no período analisado, de 0,09 anos adicionais de escolaridade esperada para cada ano do calendário.

Por volta de 1990, tem início um novo período de crescimento da escolaridade esperada. 0 início desse período coincide com as novas constituições nacional e estaduais (1988 e 1989). É também dessa época a introdução de mecanismos que reduzem as reprovações, facilitando a progressão dos estudantes, e o forte aumento da municipalização do ensino fundamental. Além disso, nesse período, houve alguma recuperação econômica, ilustrada pelo crescimento da renda per capita após 1990 (veja Figura 3), embora abaixo de nossa média histórica. Assim, há novamente aqui uma correlação entre o indicador $<E>$ e fatos marcantes da realidade brasileira, incluindo fatos econômicos. Talvez a conjunção de todos esses fatores possa explicar o forte crescimento de $<E>$ no período.

Esse último período de crescimento esgota-se por volta do ano 2000, quando tem início um novo momento de estagnação ou retrocesso, sugerindo que algumas das causas que lhe deram origem esgotaram-se. Visto que na década de 2000 houve um aumento da renda per capita nacional, bem como uma melhora em sua distribuição (HELENE, 2010), poderíamos esperar um crescimento das taxas de conclusão e, portanto, da escolaridade média esperada. Como isso não ocorreu, devemos procurar outras explicações para esse último retrocesso. Talvez o interesse dos municípios pelos recursos financeiros do FUNDEF (Fundo de Manutenção e Desenvolvimento do Ensino Fundamental e de Valorização do Magistério) possa ter levado à inclusão de crianças até então excluídas. Assim, parte do aumento de $<E>$ na década de 1990 pode ter sido um efeito conjuntural de transbordamento, como aquele que se seguiu à fusão dos antigos primário e ginásio no início da década de 1970, fazendo fluir pelo sistema pessoas que estavam represadas. Quando esgotou o estoque de excluídos que poderiam ser facilmente (e sem grande necessidade de recursos) incluídos no sistema educacional, o número de conclusões caiu. Outro efeito que pode ter-se esgotado é aquele dos programas de aprovação automática ou progressão continuada, os quais também contribuíram para manter no sistema educacional pessoas que o teriam abandonado, mas não para aumentar a inclusão ao longo do tempo.

\section{Conclusão}

Como conclusão final, podemos afirmar que tanto a estimativa da Equação (2) como a estimativa da Equação (3) representam bem o funcionamento quantitativo do sistema escolar brasileiro, podendo ser utilizadas em avaliações nos diferentes Estados ou mesmo municípios. As margens de incerteza de 3\% são suficientemente pequenas, permitindo detectar uma estagnação, um crescimento ou um retrocesso a partir do exame de $<E>$ em um período de poucos anos.

As tendências observadas nos valores de $<E>$ ao longo do tempo parecem verossímeis, não sendo fruto dos procedimentos adotados nas estimativas, pois coincidem temporalmente com outros eventos ocorridos ao longo da história do país.

Sendo corretas as estimativas de $<E>$ e sendo também corretas as correlações entre suas variações e os fatos marcantes da realidade nacional ou alterações significativas no sistema educacional (por exemplo, a fusão dos antigos 
primário e ginásio), podemos supor que uma retomada do crescimento das taxas de conclusão e da escolaridade média fornecida pelo sistema educacional venha a ocorrer de forma associada a alguma mudança significativa na realidade nacional, quer no sistema educacional, quer em outros aspectos.

$\mathrm{Na}$ década de 2000, pelo menos até o período analisado, as taxas de conclusão dos ensinos fundamental e médio foram reduzidas (veja Figura 1), e a do ensino superior teve seu ritmo de crescimento também reduzido. Entretanto, nesse mesmo período, houve uma retomada nas taxas de crescimento da renda per capita e uma melhoria na distribuição de renda, o que permitiria supor uma melhora nos indicadores de conclusão de cursos e, portanto, na escolaridade média esperada, inversamente ao que observamos. Para sabermos se essa aparente contradição é fruto apenas da exaustão do efeito de transbordamento da década de 1990 ou é uma mudança de paradigma, precisamos de análises qualitativas ou de informações quantitativas mais recentes ou mesmo futuras.

Do estudo feito por Jere Richard Behrman (1987), observamos que a evolução da escolaridade média entre 1960 e 1981, envolvendo 38 países classificados pelo autor como em desenvolvimento, correspondeu a uma média de 0,14 anos de escolaridade a cada ano do calendário. Esse valor é significativamente superior à nossa média dos últimos 90 anos (0,09 anos de escolaridade para cada ano do calendário), sugerindo que estamos perdendo posição relativamente à evolução dos demais países com iguais possibilidades e necessidades econômicas.

Tabela 1 - Conclusões dos ensinos fundamental (ou ginásio, no período anterior à fusão deste com a escola primária), médio e superior, em milhares de pessoas

\begin{tabular}{|c|c|c|c|c|c|c|c|}
\hline Ano & Fundamental & Médio & Superior & Ano & Fundamental & Médio & Superior \\
\hline 1962 & 142 & 72 & 19 & 1985 & 889 & 581 & 231 \\
\hline 1963 & 168 & 83 & 20 & 1986 & 904 & 584 & 231 \\
\hline 1964 & 192 & 96 & 20 & 1987 & 923 & 601 & 229 \\
\hline 1965 & 219 & 112 & 22 & 1988 & 965 & 620 & 227 \\
\hline 1966 & 248 & 131 & 25 & 1989 & 1016 & 638 & 227 \\
\hline 1967 & 283 & 152 & 30 & 1990 & 1082 & 657 & 231 \\
\hline 1968 & 320 & 176 & 37 & 1991 & 1159 & 681 & 235 \\
\hline 1969 & 361 & 200 & 48 & 1992 & 1276 & 735 & 238 \\
\hline 1970 & 420 & 224 & 61 & 1993 & 1421 & 815 & 241 \\
\hline 1971 & 473 & 256 & 78 & 1994 & 1575 & 897 & 247 \\
\hline 1972 & 538 & 291 & 102 & 1995 & 1745 & 1014 & 253 \\
\hline 1973 & 637 & 325 & 127 & 1996 & 1932 & 1151 & 262 \\
\hline 1974 & 832 & 349 & 149 & 1997 & 2153 & 1343 & 278 \\
\hline 1975 & 912 & 384 & 163 & 1998 & 2340 & 1552 & 300 \\
\hline 1976 & 950 & 422 & 175 & 1999 & 2506 & 1722 & 326 \\
\hline 1977 & 899 & 461 & 188 & 2000 & 2614 & 1828 & 358 \\
\hline 1978 & 954 & 486 & 200 & 2001 & 2711 & 1860 & 405 \\
\hline 1979 & 939 & 513 & 213 & 2002 & 2718 & 1864 & 463 \\
\hline 1980 & 905 & 539 & 212 & 2003 & 2636 & 1872 & 540 \\
\hline 1981 & 866 & 564 & 223 & 2004 & 2534 & 1863 & 624 \\
\hline 1982 & 866 & 578 & 227 & 2005 & 2442 & 1846 & 694 \\
\hline 1983 & 872 & 586 & 237 & 2006 & 2393 & 1803 & 737 \\
\hline 1984 & 875 & 583 & 232 & 2007 & 2314 & 1750 & 757 \\
\hline
\end{tabular}


Tabela 2 - População por faixa etária no período 1960 a 2005, em milhões de pessoas

\begin{tabular}{l|l|l|l|l|l|l|l|l|l|l|l|l}
\hline Idade & $\mathbf{1 9 6 0}$ & $\mathbf{1 9 6 5}$ & $\mathbf{1 9 7 0}$ & $\mathbf{1 9 7 5}$ & $\mathbf{1 9 8 0}$ & $\mathbf{1 9 8 5}$ & $\mathbf{1 9 9 0}$ & $\mathbf{1 9 9 5}$ & $\mathbf{2 0 0 0}$ & $\mathbf{2 0 0 5}$ \\
\hline 17,5 & 1,43 & 1,73 & 2,05 & 2,38 & 2,71 & 2,87 & 2,98 & 3,22 & 3,59 & 3,60 \\
\hline 18,5 & 1,40 & 1,68 & 1,97 & 2,30 & 2,63 & 2,79 & 2,91 & 3,11 & 3,52 & 3,56 \\
\hline 19,5 & 1,36 & 1,62 & 1,89 & 2,21 & 2,55 & 2,71 & 2,83 & 3,00 & 3,45 & 3,52 \\
\hline 20,5 & 1,32 & 1,56 & 1,81 & 2,13 & 2,47 & 2,63 & 2,76 & 2,89 & 3,37 & 3,48 \\
\hline 21,5 & 1,29 & 1,51 & 1,74 & 2,05 & 2,39 & 2,55 & 2,68 & 2,78 & 3,30 & 3,44 \\
\hline 22,5 & 1,25 & 1,45 & 1,66 & 1,97 & 2,31 & 2,47 & 2,61 & 2,67 & 3,23 & 3,40 \\
\hline 23,5 & 1,21 & 1,40 & 1,59 & 1,89 & 2,22 & 2,41 & 2,57 & 2,62 & 3,14 & 3,33 \\
\hline 24,5 & 1,17 & 1,35 & 1,52 & 1,82 & 2,14 & 2,34 & 2,53 & 2,58 & 3,05 & 3,26 \\
\hline 25,5 & 1,13 & 1,29 & 1,45 & 1,74 & 2,05 & 2,27 & 2,49 & 2,54 & 2,95 & 3,19 \\
\hline 26,5 & 1,09 & 1,24 & 1,37 & 1,66 & 1,97 & 2,21 & 2,46 & 2,49 & 2,86 & 3,11 \\
\hline 27,5 & 1,05 & 1,18 & 1,30 & 1,58 & 1,88 & 2,14 & 2,42 & 2,45 & 2,77 & 3,04 \\
\hline
\end{tabular}

Fonte: IBGE, Anuários Estatísticos, diversos anos.

Figura 1 - Taxas de conclusão dos três níveis de ensino

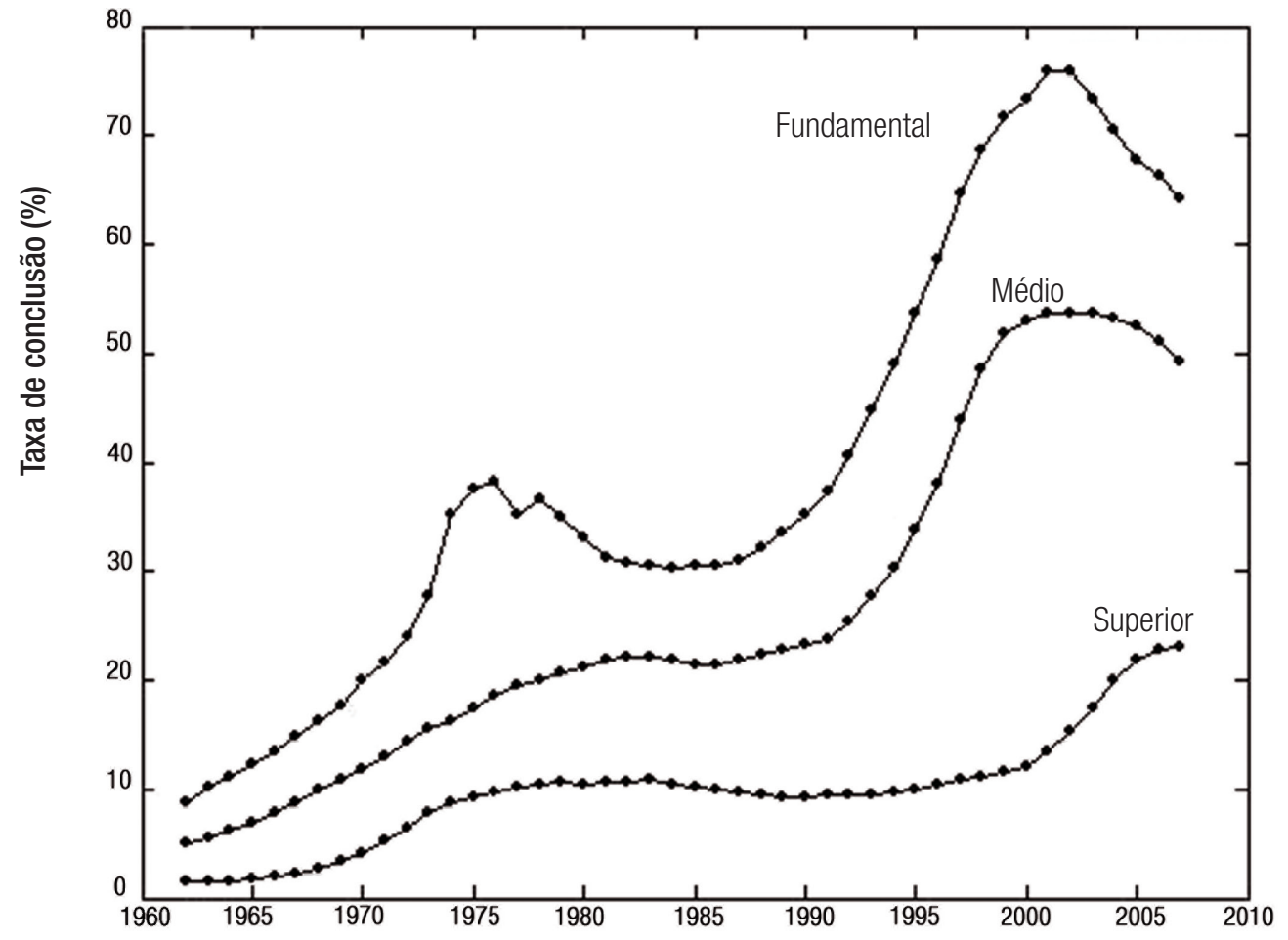


Figura 2 - Média de anos de estudo da população fornecidos pelo sistema escolar entre 1962 e 2007 (As barras correspondem a margens de incerteza de 3\%; os coeficientes de correlação entre os valores indicados são próximos a 1.)

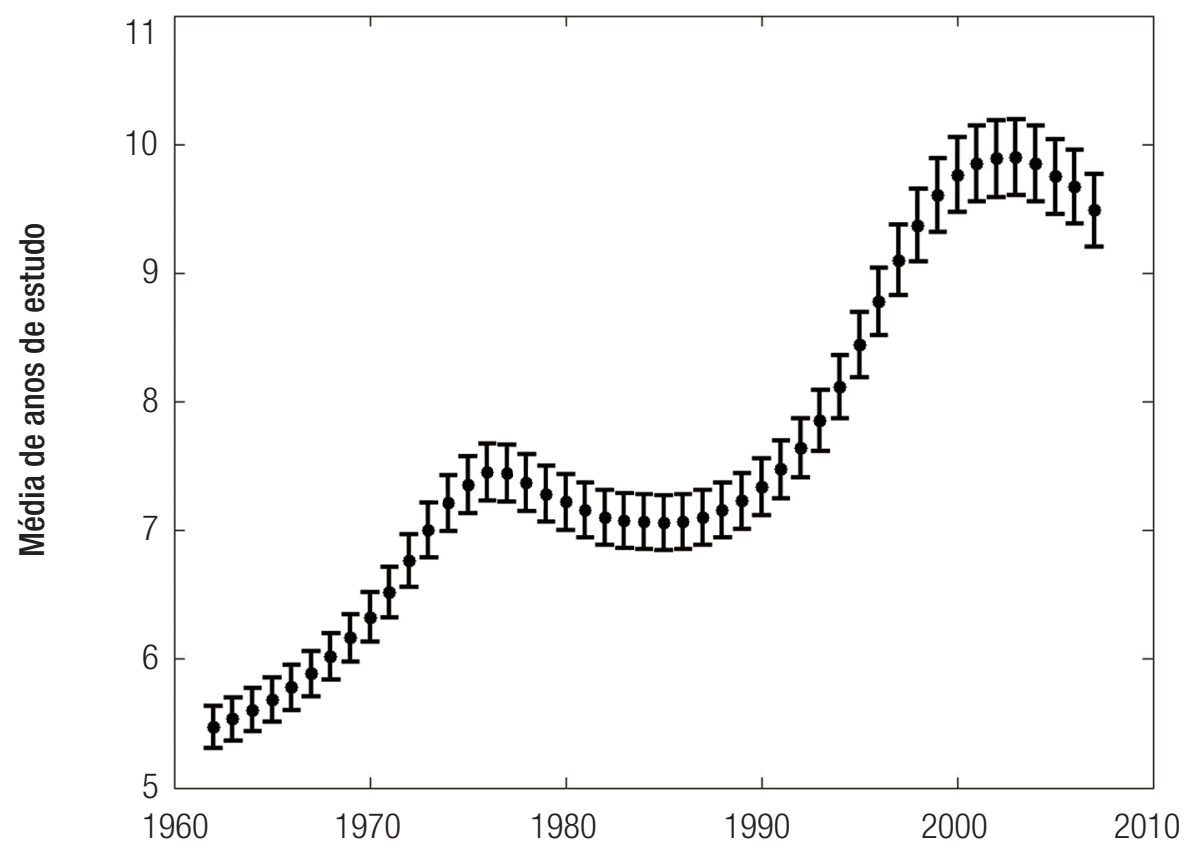

Figura 3 - Renda per capita $(1940=100)$

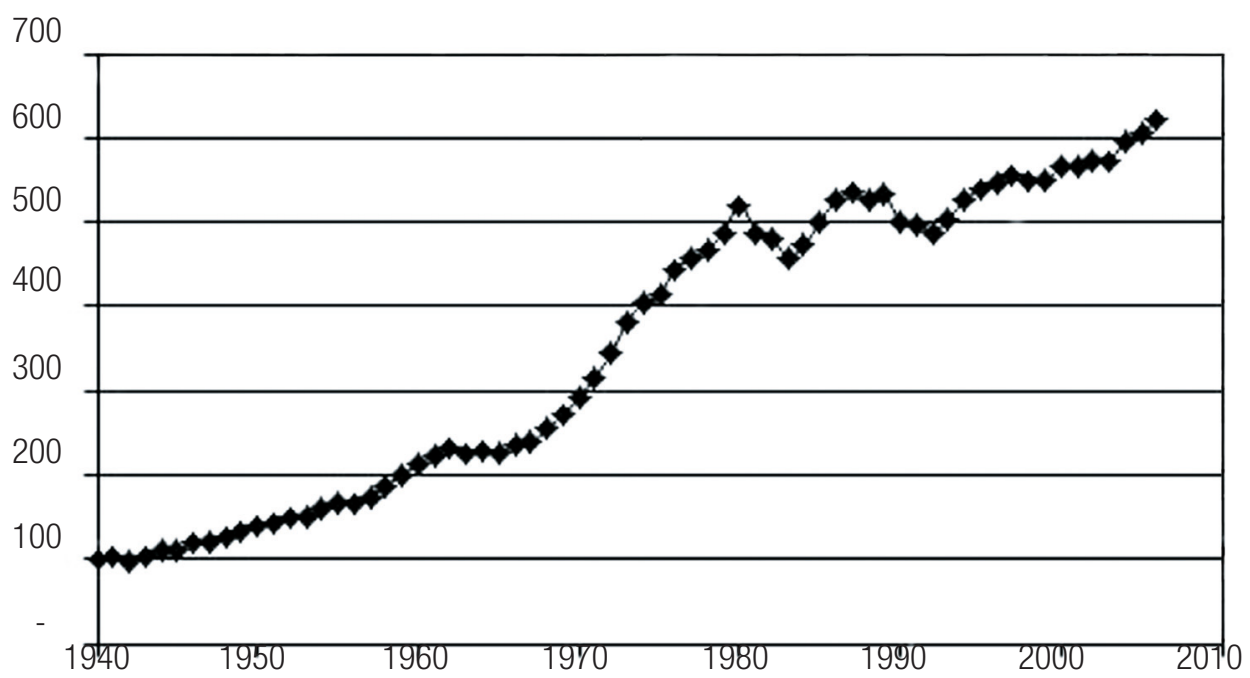


Figura 4 - Número médio de anos de estudo completados pela população em função da faixa etária

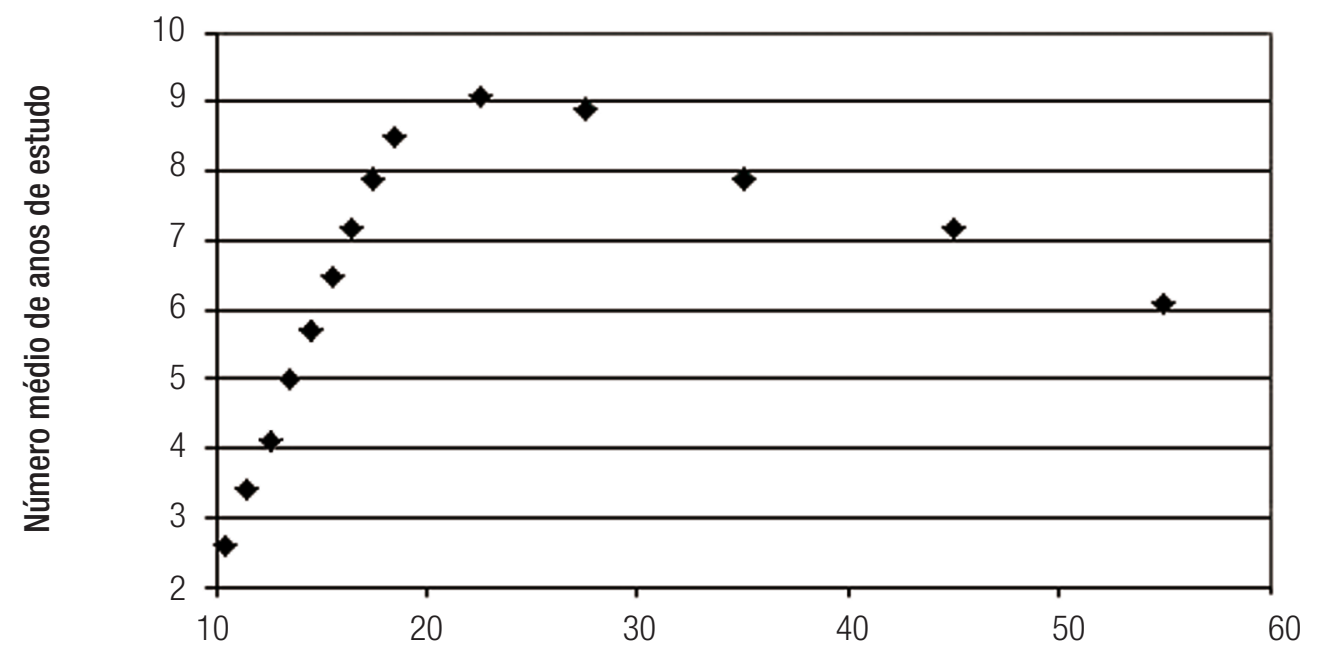

Idade média da coorte (anos)

Fonte: Pnad, 2008

Figura 5 - Estimativa da escolaridade média fornecida pelo sistema escolar calculada com base na escolaridade média declarada da população

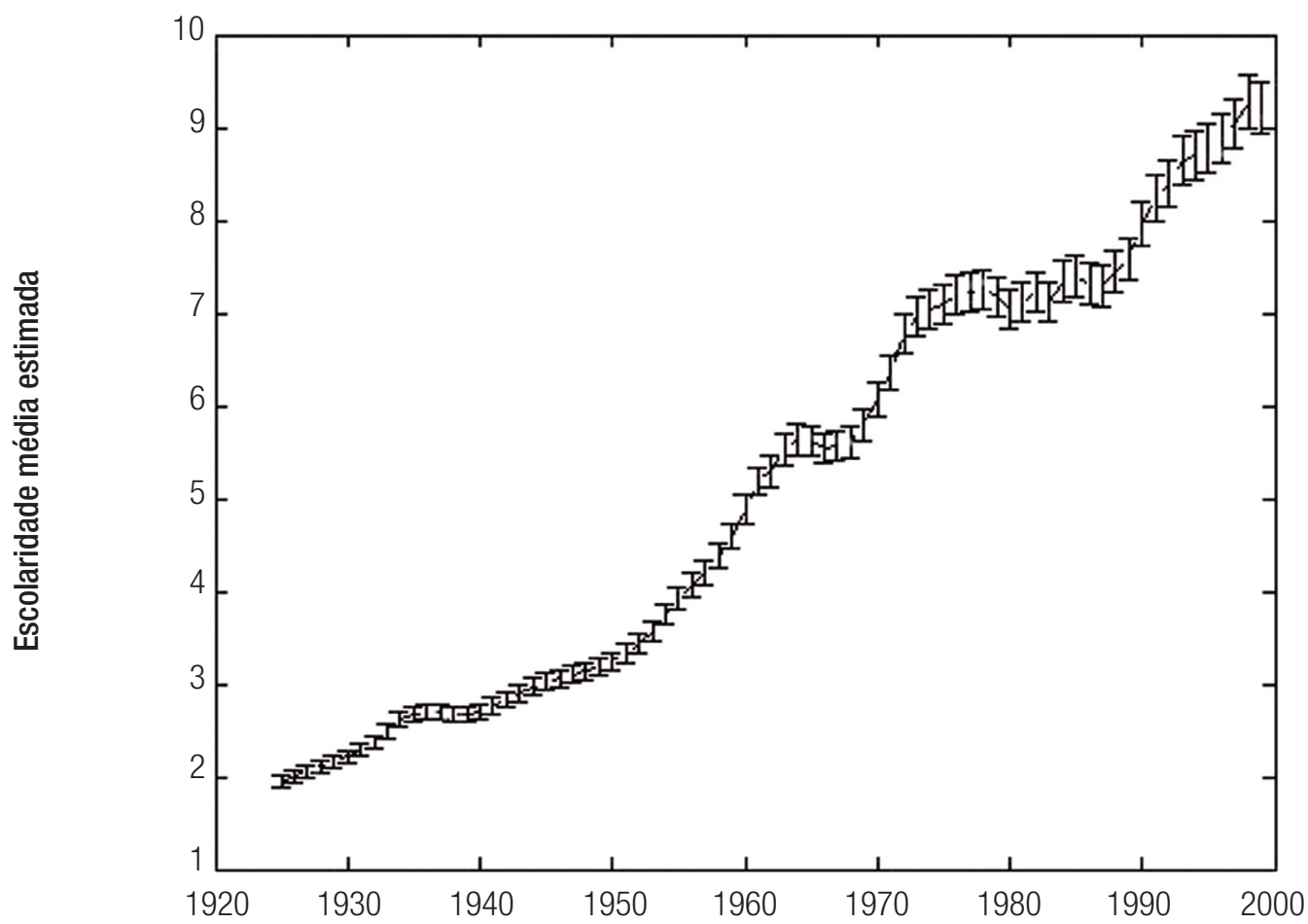


Figura 6 - Número médio de anos de estudo fornecidos pelo sistema educacional entre 1925 e 2007

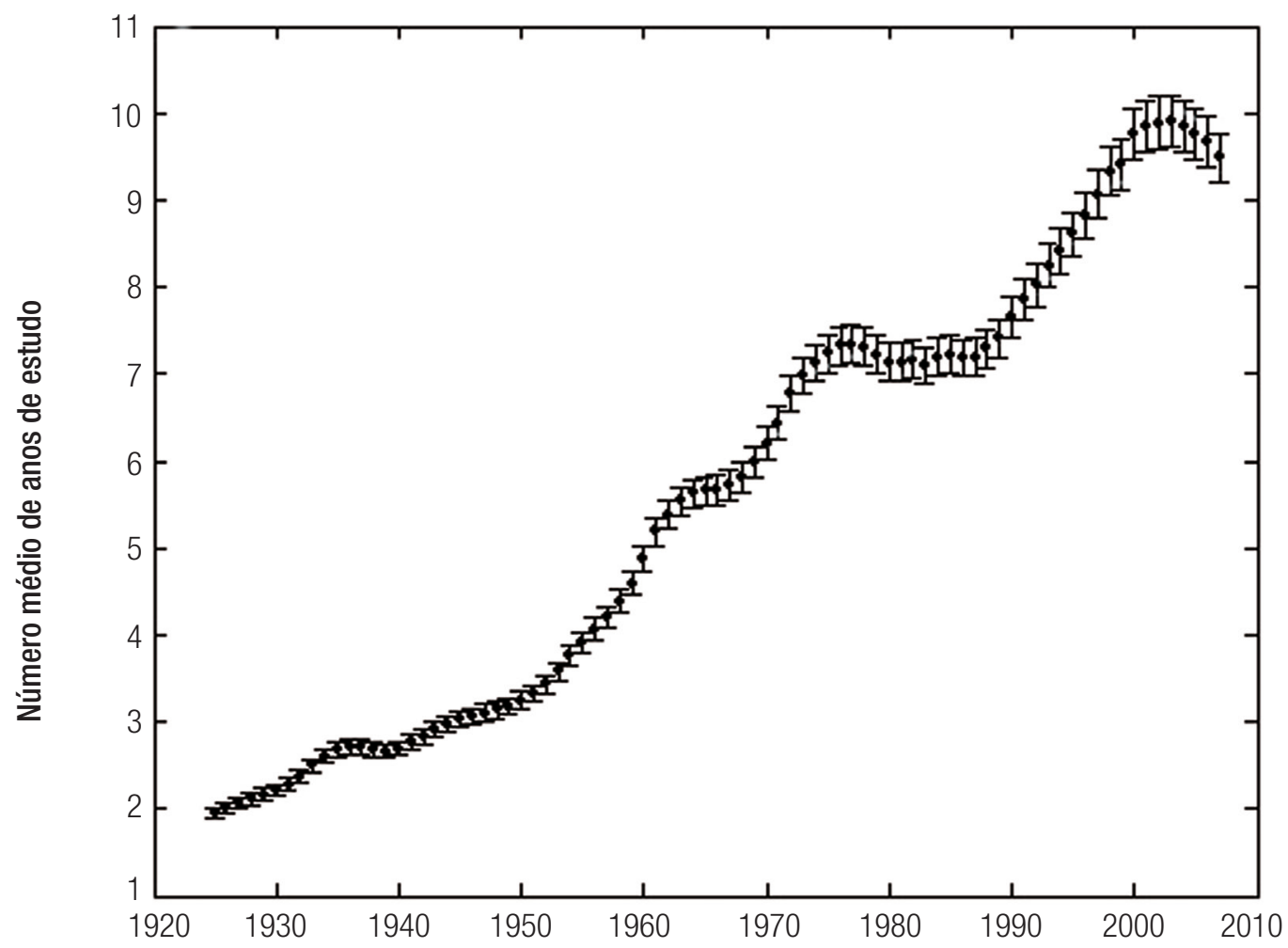

Apêndice A: Estimativa da taxa de conclusão de determinado nível educacional.

O objetivo deste apêndice é verificar a precisão da Equação (1) utilizada para estimar as taxas de conclusão de determinado nível educacional a partir dos dados comumente divulgados em uma situação na qual há variações (crescimento ou decrescimento) da população e do número de concluintes ao longo dos anos.

No que segue, discute-se o cálculo das taxas de conclusão considerando várias situações diferentes, desde uma situação em que não há variação da população e todos os estudantes concluem o nível escolar com a mesma idade, até situações em que a população das diferentes coortes etárias varia e há atrasos escolares e evasão.
Utilizaremos as seguintes notações:

$i_{0}=$ idade mínima para concluir determinado nível educacional;

$n_{i}=$ número de estudantes que, em determinado ano, concluem determinado nível educacional com idade $i$;

$N_{i}=$ população com idade $i$ (em determinado ano do calendário).

\section{Situação I: Todos os estudantes completam determinado nível educacional exatamente com a idade mínima.}

Se todos os estudantes concluem determinado nível escolar com a idade mínima (não há defasagem entre idade e série) e não há variação da população de uma coorte etária para outra, então a probabilidade de que uma pessoa conclua o nível de ensino em questão, 
mantidas inalteradas as características do sistema educacional, é simplesmente a razão entre o número de concluintes ( $\left.n_{i_{0}}\right)$ e a população na faixa etária correspondente $\left(N_{i_{0}}\right)$ :

$$
P=\frac{n_{i_{0}}}{N_{i_{0}}} \quad \text { (A-1). }
$$

Esse fator é, também, a fração da população que completará o nível de ensino em questão.
Situação II: A população em qualquer faixa etária é a mesma, mas os estudantes apresentam atrasos escolares variáveis.

Considere uma situação em que os estudantes podem acumular atraso escolar, mas a população é a mesma, independentemente da faixa etária ( $N_{i}=N_{i_{0}}$ ), para qualquer idade $i$. Nesse caso, a fração da população que completa o nível de ensino em questão em determinado ano é

$$
P=\frac{n_{i_{0}}}{N_{i_{0}}}+\frac{n_{i_{0}+1}}{N_{i_{0}+1}}+\frac{n_{i_{0}+2}}{N_{i_{0}+2}}+\ldots=\sum_{i \geq i_{0}} \frac{n_{i}}{N_{i_{0}}}=\frac{\sum_{i \geq i_{0}} n_{i}}{N_{i_{0}}}
$$

ou seja, é a razão entre o número total de concluintes, independentemente da idade, e a população em uma coorte etária de um ano.

\section{Situação III: A população varia e há atrasos} escolares.

Antes de desenvolver as equações adequadas, vamos examinar um exemplo numérico. A Tabela A-1 ilustra uma possível situação em que a idade mínima para concluir determinado nível educacional é 14 anos, mostrando tanto o número de concluintes como a população em cada uma das faixas etárias em determinado ano. (Com o objetivo de simplificar os cálculos, supôs-se que a idade máxima de conclusão é 20 anos.)

A última coluna da tabela mostra a razão entre o número de concluintes com determinada idade e a população na mesma faixa etária naquele ano. Essa coluna é, portanto, a fração da população que completará o nível de ensino em questão com a idade indicada.

\begin{tabular}{|c|c|c|c|}
\hline Idade (I) & $\begin{array}{l}\text { Número de concluintes } \\
\text { com idade i }(n)\end{array}$ & $\begin{array}{c}\text { População na coorte } \\
\text { etária }(N)\end{array}$ & Fração da população na idade $i$ que completa o nível de ensino \\
\hline 14 & 1.000 & 4.000 & 0,250 \\
\hline 15 & 500 & 3.950 & 0,127 \\
\hline 16 & 250 & 3.900 & 0,064 \\
\hline 17 & 125 & 3.880 & 0,032 \\
\hline 18 & 60 & 3.800 & 0,016 \\
\hline 19 & 30 & 3.750 & 0,008 \\
\hline 20 & 10 & 3.700 & 0,003 \\
\hline \multicolumn{3}{|c|}{ Fração total dos que completam o nível educacional } & 0,500 \\
\hline
\end{tabular}

\section{Tabela A-1}

Nesse exemplo, 25\% das pessoas completam o nível de ensino com a idade mínima - no caso, 14 anos -; 12,7\% com atraso de um ano etc. Assim, a probabilidade de que uma pessoa complete o nível de ensino em questão com qualquer idade, que é igual à fração da 
população que completará esse nível educacional, é simplesmente a soma das razões indicadas - no caso, 50\%. Em outras palavras, há $50 \%$ de chance de que uma pessoa conclua aquele nível de ensino com alguma idade, e também 50\% das pessoas o completarão em algum momento.

Embora nesse exemplo saibamos exatamente a idade dos concluintes, nem sempre esse dado está disponível. Assim, no que segue, discutiremos possíveis aproximações e examinaremos, utilizando os dados da tabela acima, a qualidade dessas aproximações.

\section{Cálculo aproximado}

A probabilidade de que uma pessoa conclua determinado nível educacional independentemente da idade é a soma das probabilidades de que ela complete esse nível com qualquer idade:

$$
P=\sum_{i \geq i_{0}} \frac{n_{i}}{N_{i}} \quad \text { (A-3) }
$$

Quando não temos informações sobre a idade de cada um dos concluintes, nem mesmo informação precisa sobre a população em cada coorte etária, é impossível calcular $P$ pela equação acima. Entretanto, como a população varia pouco entre duas coortes etárias próximas, podemos obter estimativas suficientemente precisas a partir de cálculos aproximados.

A população, em determinada coorte etária, em determinado ano $\left(\mathrm{N}_{i}\right)$, pode ser estimada a partir da população em outra coorte etária e da variação da população de uma coorte etária para outra imediatamente seguinte, naquele mesmo ano, a qual chamaremos de $a$. No exemplo em questão, podemos estimar $a$ por

$$
a \approx \frac{3700-4000}{20-14}=-50 \quad(\mathrm{~A}-4)
$$

ou seja, a cada ano adicional da faixa etária, a população decresce em 50 unidades. Essa é uma situação típica de um país cuja população está crescendo.

Assim, a população na coorte etária $i$ pode ser estimada a partir da população da coorte etária $i_{0}$ e da variação da população entre duas cortes etárias $(a)$ :

$$
N_{i} \approx N_{i 0}+a\left(i-i_{0}\right) \quad(\mathrm{A}-5) .
$$

Essa aproximação é suficientemente boa se as variações ano a ano da população não forem nem muito grandes, nem muito irregulares, como é usual.

Como na Equação (A-3) o termo $N_{i}$ aparece no denominador, outra aproximação é necessária:

$$
\frac{1}{N_{i}} \approx \frac{1}{N_{i 0}+a\left(i-i_{0}\right)} \approx \frac{1}{N_{i_{0}}}\left(1-\frac{a\left(i-i_{0}\right)}{N_{i_{0}}}\right)
$$

Substituindo esse resultado na Equação (A-3), obtemos

$$
P \approx \sum_{i \geq i_{0}} \frac{n_{i}}{N_{i}}=\sum_{i \geq i_{0}} \frac{n_{i}}{N_{i_{0}}}\left(1-\frac{a\left(i-i_{0}\right)}{N_{i_{0}}}\right)=\frac{1}{N_{i_{0}}} \sum_{i \geq i_{0}} n_{i}\left(1-\frac{a\left(i-i_{0}\right)}{N_{i_{0}}}\right)
$$


Após alguma manipulação, temos

$P \approx \frac{1}{N_{i_{0}}}\left(1-\frac{a\left(\langle i\rangle-i_{0}\right)}{N_{i_{0}}}\right) \sum_{i \geq i_{0}} n_{i}$

onde $\langle i\rangle$ é a idade média dos concluintes do nível de ensino em questão:

$$
\langle i\rangle=\frac{\sum_{i \geq i_{0}} i \cdot n_{i}}{\sum_{i \geq i_{0}} n_{i}}
$$

0 valor $\langle i\rangle-i_{0}$ é a defasagem entre idade e série.

Assim, a combinação das Equações $(A-8)$ e (A-9) permite obter, com boa aproxi- mação, a taxa de conclusão de determinado nível educacional.

\section{Exemplo}

Para avaliarmos a precisão do resultado fornecido pela Equação (A-8), vamos aplicá-la ao exemplo da Tabela A-1. A idade média dos concluintes, calculada pela Equação (A-9), é:

$$
\langle i\rangle=\frac{\sum_{i \geq i_{0}} i \cdot n_{i}}{\sum_{i \geq i_{0}} n_{i}}=14,92 \text { anos } \quad(\mathrm{A}-10)
$$

$$
P=\frac{1}{N_{i_{0}}} \sum_{i \geq i_{0}} n_{i}\left(1-\frac{a\left(\langle i\rangle-i_{0}\right)}{N_{i_{0}}}\right)=\frac{1}{4000} 1975\left[1-\frac{-50(14,92-14)}{4000}\right]=0,499 \quad \text { (A-11) }
$$

\section{Outra aproximação útil}

uma diferença desprezível quando comparada com o resultado anterior, de 0,500.
Outra aproximação igualmente boa pode ser obtida examinando-se a Equação (A-8).

$$
\frac{1}{N_{i_{0}}}\left(1-\frac{a\left(\langle i\rangle-i_{0}\right)}{N_{i_{0}}}\right) \approx \frac{1}{N_{i_{0}}+a\left(\langle i\rangle-i_{0}\right)} \approx \frac{1}{N_{\langle i\rangle}}
$$

onde $N_{\langle i\rangle}$ é a população com idade igual à idade média dos concluintes, a qual pode ser estimada a partir da distribuição da população pelas diferentes faixas etárias. Combinando esse resultado com a Equação (A-8), temos

$$
P \approx \frac{1}{N_{\langle i\rangle}} \sum_{i \geq i_{0}} n_{i} \quad(\mathrm{~A}-13)
$$

ou seja, a taxa de conclusão é igual à relação entre o número total de concluintes e a população estimada com idade correspondente à idade média dos concluintes em determinado ano.

Exemplificando com os dados da tabela A-1, temos que o número total de concluintes é $\sum_{i \geq i_{0}} n_{i}=1975$, e a população estimada com idade igual à idade média de conclusão (14,92 anos) é $N_{\langle i\rangle} \approx 3954$ pessoas (calculada pela Equação (A-5)). Assim, 


$$
P \approx \frac{1975}{3954}=0,499 \quad(\mathrm{~A}-14),
$$

valor bastante próximo a 0,500.

Podemos concluir, portanto, que as incertezas provocadas pelas aproximações numéricas são muito inferiores às incertezas cuja origem são os dados, da ordem de 3\%, como discutido no Apêndice a seguir. Uma vez que as estimativas feitas neste trabalho têm como base dados cujas variações ano a ano são menores do que as daqueles utilizados neste Apêndice, podemos supor que todos os erros de aproximações numéricas são pequenos quando comparados com incertezas originárias dos levantamentos e tratamentos dos dados.

\section{Apêndice B: Estimativas das incertezas}

Vários fatores contribuem para que os resultados obtidos referentes à escolaridade média esperada da população possam apresentar incertezas. Tais fatores são descritos a seguir, indicando-se as incertezas estimadas (correspondentes a um desvio-padrão).

a) Número de conclusões: É possível estimar as incertezas provenientes do número de conclusões em aproximadamente 1\% dos valores indicados. Esse percentual corresponde tanto à diferença entre dados divulgados por uma mesma fonte antes e depois de suas revisões, como às diferenças entre determinado valor e valores interpolados a partir de dados de anos vizinhos.

b) Estimativas da população: Diferenças nas estimativas da população e de resultados dos censos divulgados pelo IBGE são da ordem de $1 \%$. Assim, esse é outro fator a influenciar na precisão dos dados.

c) A substituição de valores por médias móveis implica variação também da ordem de $1 \%$ nos valores adotados.

d) A defasagem entre idade e série varia ao longo do sistema escolar e ao longo do tempo. A não consideração dessas variações pode levar à incerteza da ordem da variação relativa da população em duas faixas etárias distantes entre si de um tempo igual à defasagem entre idade e série. Essa incerteza foi estimada em $2 \%$.

A combinação em quadratura dessas incertezas é de aproximadamente 3\%, correspondente às barras de incerteza apresentadas nas Figuras 2, 5 e 6. 


\section{Referências}

BEHRMAN, Jere Richard. Schooling in developing countries: which countries are the over- and underachievers and what is the schooling impact? Economics of Education Review, v. 6, n. 2, p. 111-127, 1987.

FAUSTO, Boris. As crises em nossa história. Lua Nova, v. 1, n. 1, p. 79-85, jun. 1984.

FERREIRA Jr., Amarilio; BITTAR, Marisa. Educação e ideologia tecnocrática na ditadura militar. Cadernos Cedes, v. 28, n. 76, p. 333-355, set./dez. 2008.

HELENE, Otaviano. Fitting Lorenz curves. Economics Letters, v. 108, n. 2, p. 153-155, 2010.

KLEIN, Ruben. Produção e utilização de indicadores educacionais: metodologia de cálculo de indicadores do fluxo da educação básica. Revista Brasileira de Estudos Pedagógicos, v. 84, n. 206/207/208, p. 107-157, 2003.

MENDONÇA, Ana Waleska P. C. et al. Pragmatismo e desenvolvimentismo no pensamento educacional brasileiro dos anos 1950/1960. Revista Brasileira de Educação, v. 11, n. 31, p. 96, 2006.

RAM, Rati. Tropics, income, and school life expectancy: an intercountry study. Economics of Education Review, n. 18, p. 253258, 1999.

ROTHEN, José Carlos. Os bastidores da reforma universitária de 1968. Educação e Sociedade, v. 29, n. 103, p. 453-475, maio/ ago. 2008.

UNESCO. Education indicators: technical guidelines, 2009. Disponível em: <http://www.uis.unesco.org/Library/Documents/ eiguide09-en.pdf>. Acesso em: ago. 2010.

Recebido em: 11.08.2010

Aprovado em: 13.10.2011

Otaviano Helene é professor do Instituto de Física da Universidade de São Paulo e tem-se dedicado a trabalhos acadêmicos nas áreas de física experimental e tratamento estatístico de dados. Foi presidente do Instituto Nacional de Estudos e Pesquisas Educacionais Anísio Teixeira. 
